Roger Williams University

DOCS@RWU

\title{
Renal Function in Suckling and Fasting Pups of the Northern Elephant Seal
}

Dorian S. Houser

University of California, Santa Cruz

Daniel E E. Crocker

Department of Biology, Sonoma State University

Paul M. Webb

Roger Williams University, pwebb@rwu.edu

Daniel P. Costa

University of California, Santa Cruz

Follow this and additional works at: https://docs.rwu.edu/fcas_fp

Part of the Biology Commons

\section{Recommended Citation}

Houser, D. S., Crocker, D. E., Webb, P. M. and Costa, D. P. 2001. "Renal function in suckling and fasting pups of the northern elephant seal." Comparative Biochemistry and Physiology A 129:405-415.

This Article is brought to you for free and open access by the Arts and Sciences at DOCS@RWU. It has been accepted for inclusion in Arts \& Sciences Faculty Publications by an authorized administrator of DOCS@RWU. For more information, please contact mwu@rwu.edu. 


\title{
Renal function in suckling and fasting pups of the northern elephant seal
}

\author{
Dorian S. Houser ${ }^{\mathrm{a}, *}$, Daniel E. Crocker ${ }^{\mathrm{b}}$, Paul M. Webb ${ }^{\mathrm{c}}$, Daniel P. Costa ${ }^{\mathrm{a}}$ \\ ${ }^{a}$ Department of Biology, University of California, Santa Cruz, CA 95064, USA \\ ${ }^{\mathrm{b}}$ Department of Biology, Sonoma State University, Rohnert Park, CA 94928-3609, USA \\ ${ }^{\mathrm{c}}$ Department of Biology, Roger Williams University, Bristol, RI 02809, USA
}

Received 4 September 2000; received in revised form 11 December 2000; accepted 15 December 2000

\begin{abstract}
Elephant seals fast for prolonged periods without access to water. This is made possible, in part, by reductions in urine production. However, the mechanisms involved in reducing urine production are not understood. In this study, glomerular filtration rate (GFR) was measured in five northern elephant seal pups (Mirounga angustirostris) via the inulin clearance technique. Measurements were made during day 9 and day 18-22 of nursing and the second and eighth week of the postweaning fast. Plasma aldosterone and cortisol concentrations, quantified by radioimmunoassay, were measured in eight other weanlings during the second and eighth week of the fast. Mean GFR was $79.3 \pm 29.3 \mathrm{ml} / \mathrm{min}$ during the early suckling period and 78.2 $\pm 17.1,89.8 \pm 52.7$, and $80.4 \pm 12.2 \mathrm{ml} / \mathrm{min}$ during the late suckling, early fasting and late fasting periods, respectively. Differences between nursing and fasting were insignificant, possibly because reduced protein oxidation during suckling and rapid recruitment of protein for tissue synthesis obviated the need for postprandial hyperfiltration. Alternatively, maintenance of GFR during fasting may facilitate urea concentration by compensating for reductions in the fractional excretion of urea. It is further hypothesized that aldosterone is primarily responsible for mediating renal water reabsorption in this system. (c) 2001 Elsevier Science Inc. All rights reserved.
\end{abstract}

Keywords: Aldosterone; Cortisol; Glomerular filtration rate (GFR); Inulin; Kidney; Urine; Urea; Water conservation

\section{Introduction}

Northern elephant seals (Mirounga angustirostris) completely abstain from food and water during periods of intense terrestrial activity and

\footnotetext{
* Corresponding author. SPAWARSYSCEN-San Diego, Navy Marine Mammal Program, Code 351, 49620 Beluga Road, San Diego, CA 92152-6506, USA. Tel.:+1-619-5539058; fax: + 1-619-553-1355.

E-mail address: dhouser@spawar.navy.mil (D.S. Houser).
}

energy expenditure, and during postweaning development (Le Boeuf and Peterson, 1969; Ortiz et al., 1978; Costa et al., 1986). During the breeding season, adult male elephant seals fast as they aggressively compete for position within a dominance hierarchy, and adult females suckle their pups while fasting (Le Boeuf, 1974; Reiter et al., 1981). For 2-3 months following weaning, pups fast as they progressively develop the diving skills necessary for pelagic foraging (Reiter et al., 1978; Thorson and Le Boeuf, 1994). During these peri- 
ods, elephant seals abstain from water consumption, but maintain water balance through several physiological and behavioral adaptations (Huntley et al., 1984; Adams and Costa, 1993; Blackwell and Le Boeuf, 1993). The ability to maintain water balance throughout extended periods of fasting presumably contributes to beach residency time, which in turn affects the maternal investment and reproductive effort of adults, and the physiological and behavioral development of pups prior to their initial migration.

Weaned elephant seals do not consume water during fasting, and contributions to the body water are restricted to metabolic water production, primarily as a result of lipid catabolism (Ortiz et al., 1978; Castellini et al., 1987). Significant reductions in both evaporative and urinary water loss help to maintain positive water balance (Ortiz et al., 1978). Respiratory evaporative water loss is reduced by a combination of apneustic breathing and the presence of an exceptional counter-current nasal heat-exchanger (Huntley et al., 1984; Blackwell and Le Boeuf, 1993). A very low rate of protein oxidation during fasting, coupled with an efficient urine-concentrating mechanism, reduces urinary water loss (Ortiz et al., 1978; Pernia et al., 1989; Adams and Costa, 1993). Weanlings decrease urine production by $84 \%$ across the fast, from $433 \mathrm{ml}$ urine/day during the first week of the fast to $64 \mathrm{ml}$ urine/day during the 10th week of the fast (Adams and Costa, 1993). However, it is unclear whether the mechanism underlying reduced urine production is decreased glomerular filtration or increased tubular reabsorption (Pernia et al., 1989; Adams and Costa, 1993).

Typically, glomerular filtration rate (GFR) increases by as much as $200 \%$ after feeding (Hladky and Rink, 1986) and declines by up to $32 \%$ in fasted or nutrient-deprived mammals (Pullman et al., 1954; Brown et al., 1971; Boim and Schor, 1992; Bosch, 1995). Previous work on elephant seals has failed to demonstrate this typical mammalian response. For example, there was no difference in GFR between fasted elephant seal weanlings and those fed a diet of fish (Pernia et al., 1989). However, the timing of sample collection varied by as much as 5-10 h post-feeding, thereby making any consistent postprandial change in GFR difficult to quantify. In contrast, postprandial hyperfiltration was observed in the confamilial harbor seal (Phoca vitulina) (Hiatt and Hiatt, 1942). Further research on renal function in elephant seals is warranted, as earlier work may have missed changes in GFR associated with feeding or fasting. It remains unclear whether reduced urine production in fasting elephant seals is due to reductions in GFR or to increased tubular reabsorption.

In mammals, vasopressin, aldosterone, and angiotensin II regulate tubular water reabsorption. One method of assessing the importance of tubular reabsorption in elephant seal urine concentration is to follow changes in these regulatory hormones. Specifically, do vasopressin, aldosterone, and angiotensin II have the same roles in regulating tubular reabsorption in elephant seals as observed for other mammals? Vasopressin primarily affects water reabsorption within the collecting duct, but Ortiz et al. (1996) found no correlation between plasma vasopressin concentration and urine concentrating ability in fasting elephant seal weanlings. Aldosterone and angiotensin II impact water reabsorption by acting on sodium conservation in the collecting duct and proximal tubule, respectively, but their potential effect on water economy in this species has yet to be rigorously investigated.

The purpose of this study was to examine renal filtration under feeding and fasting conditions and to address changes in anti-diuretic hormones across the fast in northern elephant seal pups. Postprandial GFR measurements obtained during suckling address renal function in animals that are simultaneously processing and absorbing materials. Measurements taken during the postweaning fast address temporal changes in renal function associated with prolonged water abstinence. Comparisons between feeding and fasting periods allow an assessment of nutrient/water-dependent renal filtration responses. The hormonal control of water reabsorption was examined by correlating serum aldosterone concentrations measured during the fast with known time-dependent changes in urine osmolarity.

\section{Materials and methods}

\subsection{Glomerular filtration rate (GFR)}

All sampling procedures were conducted at the Año Nuevo State Reserve, San Mateo County, California, during the 1994-1995 breeding sea- 
son. Upon arrival at the rookery, known-age adult female elephant seals were identified by their flipper tags (Dalton jumbo Roto-tags, Oxon., England). Parturition dates were recorded and pups born to adult females between 6 and 9 years of age were monitored for 7 days postpartum. Within 2 days following parturition, adult females were marked with Lady Clairol blue/black hair dye (Stamford, CT) and pups were marked with bleach (Le Boeuf and Peterson, 1969). Mother-pup pairs were observed for normal behavioral patterns and apparent health. Five pups (three males, two females) were selected from this group for GFR measurements.

Glomerular filtration rate was measured four times, twice during suckling and twice during the fasting period. Measurements during suckling were made at 9 and 18-22 days postpartum, and during the fast at 2 and 8 weeks postweaning. All pups were weaned within what is considered to be the normal suckling period for northern elephant seals ( $\sim 27$ days, Le Boeuf et al., 1972; Reiter et al., 1978) and all appeared to be in good physical condition at the end of the fast (2-3 months postweaning).

Suckling pups were separated from their mothers for the duration of the sampling period $(\sim 3$ h) and placed on a PVC restraint board. Weanling seals were immobilized by a $1-\mathrm{mg} / \mathrm{kg}$ intramuscular injection of tiletamine-zolazepam (tiletamine $\mathrm{HCl} /$ zolazepam $\mathrm{HCl}$ in a $1: 1$ ratio; Telazol; Fort Dodge, Iowa). Intravenous bolus injections of $0.5 \mathrm{mg} / \mathrm{kg}$ ketamine were administered as needed to maintain immobilization (Briggs et al., 1975). Mass was measured at the end of each sampling period by placing each pup in a nylon restraint bag and suspending it from an aluminum tripod with a Chatillion WT-10 scale (capacity $1000 \pm 5 \mathrm{lbs}$ ) and hand winch.

Prior to the administration of inulin, a blood sample was collected in a 5-ml Na-heparin vacutainer. All study animals were then given a bolus injection of $\left[{ }^{3} \mathrm{H}\right]$ methoxy-inulin (LadegaardPedersen, 1972) in a 1:10 ratio with sterile water. Pups were given $0.1 \mathrm{mCi}$ of $\left[{ }^{3} \mathrm{H}\right]$ methoxy-inulin at 9 days postpartum and $0.2 \mathrm{mCi}$ at $18-22$ days postpartum and during the second and eighth week of the postweaning fast. Injections of tracer were made in the posterior region of the dorsal extradural vein with a 3.5-inch 18-gauge spinal needle. Blood samples were taken post-injection at 5-min intervals for $30 \mathrm{~min}$. Further samples were then taken every 15 min until the end of the third $\mathrm{h}$. Collections were made into 5-ml Naheparin vacutainers, gently agitated, and placed on ice. Centrifugation and collection of the supernatant plasma from all samples occurred within 1 $h$ of collection of the final sample.

Aliquots of plasma $(100-400 \mu \mathrm{l})$ were combined with $5 \mathrm{ml}$ of Ecolite scintillation cocktail (ICN; Costa Mesa, CA). The tritium activity of each sample was determined in triplicate with a Beckman LS 3801 liquid scintillation counter using standard scintillation techniques. A quenchcorrection curve was established using tritiated water standards of identical activity, but with variable degrees of quench, and a counter-determined correction factor $(\mathrm{H \# )}$ was established for each. The activity of standards was regressed against $\mathrm{H \#}\left(R^{2}=0.99\right)$, and the resultant regression line was used to correct sample quench due to hemolysis, lipemia, or plasma coloration.

Glomerular filtration rate was determined for each pup using a single-injection model (Ladegaard-Pedersen, 1972; Hall et al., 1977; Pernia et al., 1989), in which GFR is calculated from the total clearance curve of the radioisotope. The clearance curve was fitted with three mono-exponential non-linear least squares models, on the assumption that the isotope was simultaneously distributed and cleared in three distinct steps: (1) distribution into the main blood pool; (2) equilibration into the extracellular volume (ECV); and (3) clearance of the tracer by simple glomerular filtration, independent of any other equilibration process. Determinations of the line representing simple GFR always had $R^{2}>0.90$. GFR was calculated as:

$\mathrm{GFR}=Q / \int A_{t}(t) \mathrm{d} t$

where $Q$ is the tritium activity of injected tracer, $A_{t}$ is the plasma activity of $\left[{ }^{3} \mathrm{H}\right]$ inulin at time $t$, and the integral is evaluated from $t=0$ to $\infty$. Integration was used to determine the area under the bounded region described by each mono-exponential equation, and the individual areas were summed. Extracellular volume was evaluated as:

$E C V=Q \cdot\left(\int t A_{t}(t) \mathrm{d} t\right) /\left[\int A_{t}(t) \mathrm{d} t^{2}\right]$

and was calculated over the same interval.

Plasma obtained from pre-injection blood samples was used to spectrophotometrically de- 
termine blood urea nitrogen (BUN) concentrations and plasma creatinine concentrations using Sigma diagnostic kits \#535 and \#555 (Sigma Diagnostics; St. Louis, MO), respectively.

\subsection{Aldosterone and cortisol}

In 1997, blood samples were taken from 10 manually restrained weanling seals during the second week of the postweaning fast. Repeat blood collections were made on eight of these seals during eighth week of the fast. Blood was collected via the extradural vein into $13.0-\mathrm{ml} \mathrm{Na}-$ heparinized vacutainers, gently agitated, and placed on ice. After centrifugation, the plasma was drawn off and frozen at $-20^{\circ} \mathrm{C}$ until the time of processing. In addition to a radioimmunoassay (RIA) for aldosterone, a RIA for cortisol was performed to determine if cortisol and aldosterone concentrations were correlated. A positive correlation between cortisol and aldosterone concentration may be indicative of increased aldosterone production due to handling stress.

Concentrations of immunoreactive aldosterone and cortisol were determined using commercially available RIA kits (Diagnostics Products Corporation; Los Angeles, CA). Assay tubes were counted in a Packard Multi-Prias gamma counter. The $\%$ recovery of radioinert aldosterone and cortisol was 82.8 and $92.4 \%$, respectively. Significant parallelism of serially diluted pools of northern elephant seal plasma was observed for both assays. For both aldosterone and cortisol, all samples were analyzed in the same assay with intraassay coefficients of variability of $<8.0 \%$ and $<4.0 \%$, respectively.

\subsection{Data analysis}

Repeated measures ANOVA was used to compare measured variables from each treatment. In instances when the data failed a normality test, repeated measures ANOVA on ranks was used. Multiple treatment comparisons were made using a Tukey test, and comparisons between two categories were made using a pairwise $t$-test. Linear regression was used to test the relationship between BUN and creatinine ratios $(\mathrm{B} / \mathrm{C})$ and renal function. Because matched samples were not made for every subject throughout the study, subject-specific data points were randomly eliminated from the data set, such that each subject was represented twice within the regression analysis. Statistical tests were performed with SIGMASTAT $^{\odot} 2.0$ software (SPSS Inc., Chicago, IL). All tests held $\alpha=0.05$.

\section{Results}

\subsection{Mass and extracellular volume (ECV)}

Mass, ECV, ECV/mass, BUN and creatinine are presented for each pup and nutritional state in Table 1. Mass gain during the nursing period averaged $4.39 \mathrm{~kg}$ /day and mean mass loss over the fast was $0.69 \mathrm{~kg} /$ day. Rates of mass gain and loss across suckling and fasting were similar to previously reported values, suggesting that experimental subjects were representative of typical seal pups (Ortiz et al., 1978, 1984; Rea and Costa, 1992).

Mean values of ECV appeared reasonable, but individual determinations of the proportion of mass due to the ECV exceeded or fell below physiological expectation. The underlying cause was likely due to a violation of model assumptions (see Section 4), and as a result, calculated ECV was not used in further analysis.

\subsection{Glomerular filtration rate (GFR)}

Longitudinal changes in the absolute GFR of individuals were variable, ranging from 45.0 to $175.9 \mathrm{ml} / \mathrm{min}$, and no trends were evident (Fig. 1). Mean GFR did not vary significantly between fasting and nursing, or between early and late measurements taken under fasting or feeding conditions $(F=0.13, \quad P=0.94)$. Mean massspecific GFR decreased from $1.40 \mathrm{ml} / \mathrm{min} \mathrm{kg}$ during the early suckling period to $0.71 \mathrm{ml} / \mathrm{min}$ $\mathrm{kg}$ during the late suckling period and then increased slightly into the fast (Fig. 2), but no significant differences were observed between nursing and fasting categories $\left(X^{2}=3.96, P=\right.$ 0.27). As with absolute GFR, individual rates of mass-specific GFR were variable within and across nutritional categories and demonstrated no obvious trends.

Because feeding may impact renal function (Hladky and Rink, 1986), GFR for suckling and fasting periods was separated, and regression analysis was applied to each data set separately. No significant relationship was found to exist 
Table 1

Mass, extracellular volume (ECV), proportional contribution of ECV to mass, BUN and creatinine for individuals and nutritional states

\begin{tabular}{|c|c|c|c|c|c|c|}
\hline Animal ID & Nutritional state & $\begin{array}{l}\text { Mass } \\
(\mathrm{kg})\end{array}$ & $\begin{array}{l}\text { ECV } \\
\text { (1) }\end{array}$ & $\begin{array}{l}\mathrm{ECV} / \text { mass } \\
(1 / \mathrm{kg})\end{array}$ & $\begin{array}{l}\text { BUN } \\
(\mathrm{mg} / \mathrm{dl})\end{array}$ & $\begin{array}{l}\text { Creatinine } \\
(\mathrm{mg} / \mathrm{dl})\end{array}$ \\
\hline W1 & \multirow[t]{6}{*}{ Early suckling } & 61.0 & 6.32 & 0.10 & 35.34 & 0.90 \\
\hline W2 & & 66.0 & 13.66 & 0.21 & 22.57 & 2.01 \\
\hline W3 & & 62.0 & 11.89 & 0.19 & 20.37 & 0.81 \\
\hline W4 & & 65.0 & 24.69 & 0.38 & $-{ }^{\mathrm{a}}$ & $-^{\mathrm{a}}$ \\
\hline W5 & & 45.5 & 10.43 & 0.23 & 10.15 & 0.87 \\
\hline Mean $( \pm$ S.D. $)$ & & $59.9 \pm 8.3$ & $13.40 \pm 6.87$ & $0.22 \pm 0.10$ & $22.11 \pm 10.35$ & $1.15 \pm 0.58$ \\
\hline W1 & \multirow[t]{6}{*}{ Late suckling } & 111.0 & 18.91 & 0.17 & 50.03 & 1.61 \\
\hline W2 & & 125.0 & 22.12 & 0.18 & 25.90 & 0.98 \\
\hline W3 & & 134.0 & 17.46 & 0.13 & 27.61 & 0.84 \\
\hline W4 & & 97.0 & 17.02 & 0.18 & 29.74 & $-{ }^{\mathrm{a}}$ \\
\hline W5 & & 87.0 & 16.11 & 0.19 & 34.14 & 1.18 \\
\hline Mean $( \pm$ S.D. $)$ & & $110.8 \pm 19.3$ & $18.32 \pm 2.35$ & $0.17 \pm 0.02$ & $33.48 \pm 9.75$ & $1.15 \pm 0.33$ \\
\hline W1 & \multirow[t]{6}{*}{ Early fast } & 120.0 & 17.38 & 0.14 & 46.27 & $-^{\mathrm{a}}$ \\
\hline W2 & & 125.0 & 20.80 & 0.17 & 16.25 & 1.23 \\
\hline W3 & & 125.0 & 42.19 & 0.34 & 21.29 & 1.08 \\
\hline W4 & & 93.0 & 10.89 & 0.12 & 30.73 & 1.13 \\
\hline W5 & & 110.0 & 16.76 & 0.15 & 30.16 & 0.92 \\
\hline Mean $( \pm$ S.D. $)$ & & $114.6 \pm 13.5$ & $21.6 \pm 12.05$ & $0.18 \pm 0.09$ & $28.94 \pm 11.45$ & $1.09 \pm 0.13$ \\
\hline W1 & \multirow[t]{6}{*}{ Late fast } & 96.0 & 17.39 & 0.18 & 42.37 & 1.55 \\
\hline W2 & & 84.0 & 12.64 & 0.15 & 7.31 & 0.69 \\
\hline W3 & & 100.0 & 12.67 & 0.13 & 15.33 & 0.91 \\
\hline W4 & & 71.0 & 26.39 & 0.37 & 12.92 & 0.71 \\
\hline W5 & & 90.0 & 28.80 & 0.32 & $-{ }^{\mathrm{a}}$ & $-{ }^{\mathrm{a}}$ \\
\hline Mean $( \pm$ S.D. $)$ & & $88.2 \pm 11.4$ & $19.58 \pm 7.62$ & $0.23 \pm 0.11$ & $19.48 \pm 15.62$ & $0.96 \pm 0.40$ \\
\hline
\end{tabular}

${ }^{\mathrm{a}}$ Sample was not taken.

between GFR and mass under either suckling or fasting conditions $\left[R^{2}<0.01, P=0.96\right.$ (suckling); $R^{2}=0.12, P=0.32$ (fasting)]. The ratio of blood urea nitrogen to serum creatinine concentration has been used as a predictor of GFR (Finko et al., 1995), but $\mathrm{B} / \mathrm{C}$ ratios were not significantly

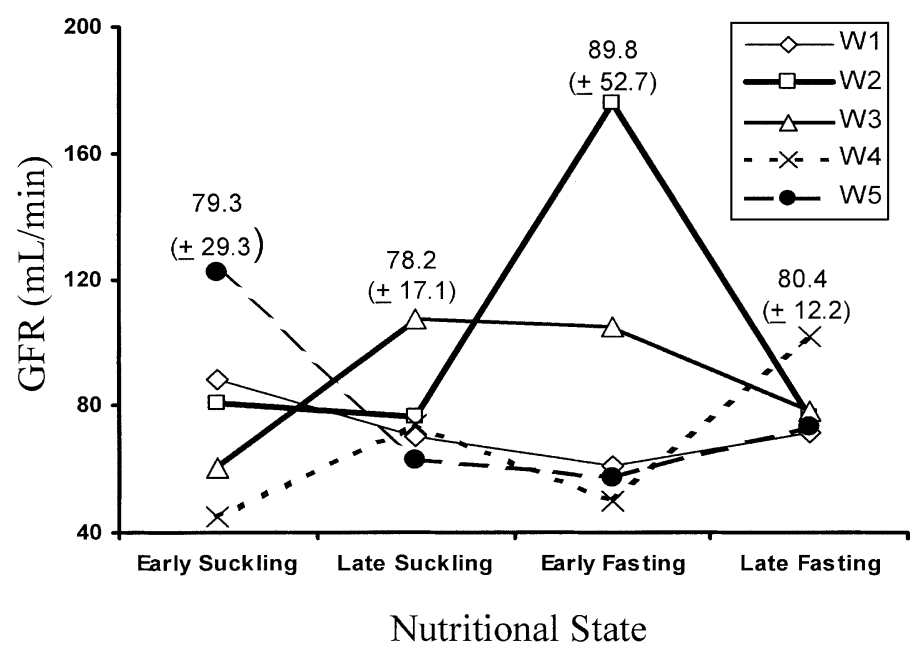

Fig. 1. Change in absolute GFR as a function of varying nutritional state. Means $( \pm$ S.D.) are presented above individual values for each nutritional state. 


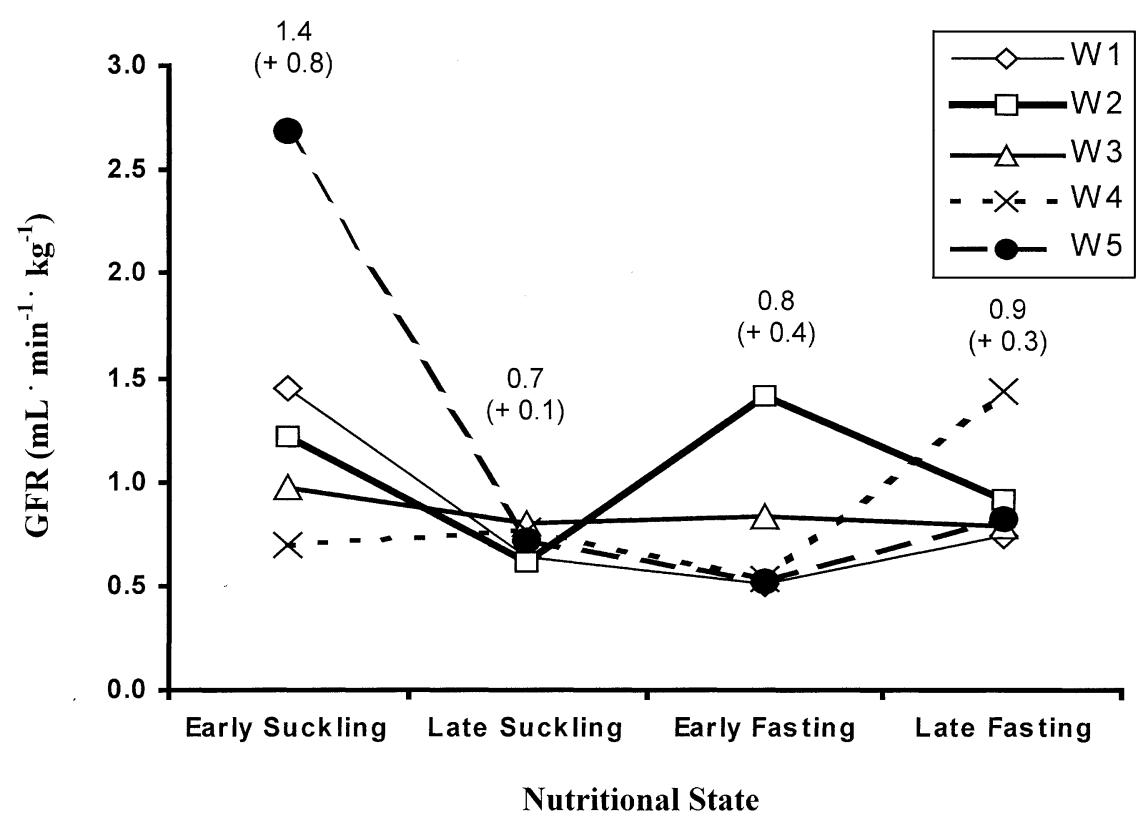

Fig. 2. Change in mass-specific GFR as a function of varying nutritional state. Means ( \pm S.D.) are presented above individual values for each nutritional state.

correlated to either GFR $\left(R^{2}=0.08, P=0.35\right)$ or mass-specific GFR $\left(R^{2}=0.18, P=0.14\right)$.

\subsection{Aldosterone and cortisol}

Repeat measures of aldosterone and cortisol were made in eight of the 10 animals sampled during the postweaning fast. Two of the seals were not found during the eighth week of the fast, and comparisons between early and late fasting samples were restricted to matched pairs. Cortisol ranged from 2.79 to $23.3 \mu \mathrm{g} / \mathrm{dl}$ across the fast, and varied less amongst individuals during the second week (Table 2). In contrast, plasma aldosterone concentrations ranged from 118 to $890 \mathrm{pg} / \mathrm{ml}$ and were more stable during the eighth week of the fast. The correlation between cortisol and aldosterone was low $\left(R^{2}=-0.07\right)$, suggesting that there were no acute increases in aldosterone production as a result of elevated cortisol. Plasma cortisol concentrations increased between the second and eighth week of the fast, but differences were not significant $(t=-2.11, P=$ 0.07). Plasma aldosterone concentrations signifi-

Table 2

Plasma cortisol and plasma aldosterone concentrations measured early ( 2 weeks) and late ( 8 weeks) in the postweaning fast

\begin{tabular}{|c|c|c|c|c|}
\hline \multirow[t]{2}{*}{ Animal ID } & \multicolumn{2}{|c|}{ Cortisol ( $\mu \mathrm{g} / \mathrm{dl})$} & \multicolumn{2}{|c|}{ Aldosterone $(\mathrm{pg} / \mathrm{ml})$} \\
\hline & Early & Late & Early & Late \\
\hline 1 & 4.4 & 5.3 & 337.9 & 118.1 \\
\hline 2 & 9.0 & 5.1 & 492.0 & 166.8 \\
\hline 3 & 5.8 & 23.3 & 180.6 & 246.0 \\
\hline 4 & 3.1 & 6.4 & 406.9 & 128.3 \\
\hline 5 & 5.2 & 14.8 & 890.5 & 633.9 \\
\hline 6 & 2.8 & 10.0 & 439.9 & 232.0 \\
\hline 7 & 4.5 & 6.2 & 357.5 & 447.0 \\
\hline 8 & 5.3 & $-^{\mathrm{a}}$ & 256.2 & $-{ }^{\mathrm{a}}$ \\
\hline 9 & 4.2 & $--^{\mathrm{a}}$ & 736.2 & $--^{\mathrm{a}}$ \\
\hline 10 & 4.7 & 7.3 & 740.6 & 359.0 \\
\hline Mean $( \pm$ S.D. $)$ & $4.9 \pm 1.7$ & $9.8 \pm 6.3$ & $483.8 \pm 231.9$ & $291.4 \pm 178.8$ \\
\hline
\end{tabular}

${ }^{\mathrm{a}}$ Animal not found during final sampling period. 
cantly decreased between weeks 2 and 8 of the fast $(t=3.08, P=0.02)$.

\section{Discussion}

Individual variation in renal filtration emphasizes the labile nature of renal function within the northern elephant seal pup. Most mammals, including the confamilial harbor seal, consistently demonstrate a postprandial hyperfiltration and a reduction in filtration associated with the cessation of food and water consumption (Hiatt and Hiatt, 1942; Pullman et al., 1954; Brown et al., 1971; Nelson et al., 1973; Hladky and Rink, 1986; Boim and Schor, 1992; Bosch, 1995). In this study, the broad variability in GFR and mass-specific GFR, independent of food and water abstention or consumption, defines neither a postprandial hyperfiltration, nor a hypofiltration due to fasting or water abstention.

Measurements of GFR obtained in this study are similar to the measurements obtained by Pernia et al. (1989), who presented two hypotheses as to why consistent changes in GFR were not observed between fasting and feeding weanling seals. They first suggested that the similarity in GFR between feeding and fasting groups was possibly a consequence of the sampling schedule employed. Measurements of GFR were made 5-10 h after feeding, potentially missing a postprandial increase in GFR associated with digestion and absorption. They alternatively suggested that feeding elephant seal pups, which are in a period of rapid growth, might reduce urea formation by rapidly recruiting protein for tissue synthesis, and thus obviate an increase in GFR. This hypothesis is supported by research indicating that suckling pups spare protein in proportions similar to that observed during fasting (Houser, 1998), and that weanlings fed a diet of squid and anchovies continue to preferentially catabolize fat and spare protein for tissue synthesis (Condit and Ortiz, 1987). Insignificant differences in matched sample comparisons between suckling and fasting periods presented here also support this latter hypothesis. Suckling-age pups were certainly in a state of digestion/absorption at the time of sampling, yet GFR remained comparable to rates observed in fasting weanlings. Thus, any postprandial hyperfiltration was minor and likely pre- cluded by the demand for rapid tissue synthesis (i.e. minimal urea production).

Regardless of whether or not a postprandial increase in GFR exists, filtration rates between suckling and fasting periods are not significantly different, have similar mean values and demonstrate considerable functional plasticity. This is a markedly different response than the pronounced and consistent reduction in GFR observed in other mammals under reduced nutritional intake or transitioning into natural or forced fasts (Pullman et al., 1954; Brown et al., 1971; Boim and Schor, 1992; Bosch, 1995). It is also contradictory to estimates of renal filtration in weanling elephant seals based upon creatinine clearance (Adams and Costa, 1993). Adams and Costa estimated that GFR declined from 67 to $35 \mathrm{ml} / \mathrm{min}$ across the first 10 weeks of fasting. However, GFR determined through creatinine clearance is not as accurate as determinations made with inulin clearance, because creatinine can be secreted by renal tubules. Any fasting-induced change in tubule creatinine secretion may thus result in faulty estimates of renal filtration. Rates of creatinine secretion by renal tubules need to be determined in elephant seals at different times during the fast in order to assess whether variation in creatinine secretion underlies the contrasting results of studies employing different methodologies (i.e. inulin vs. creatinine clearance).

Pernia et al. (1989) hypothesized that fasting elephant seal pups may maintain GFR at pre-fasting levels provided tissue metabolism produced a sufficiently large nitrogen and electrolyte load to necessitate it. The assumed rate of muscle catabolism they used to demonstrate this was necessarily high (135 g/day), however, and not likely representative of average muscle catabolism rates of fasting weanlings (Houser, 1998). Crocker et al. (1998) observed that GFR in simultaneously fasting and lactating female elephant seals increased across the fast, and hypothesized that elevated GFR improved the efficiency of urea excretion. In this mechanism, elevated GFR reduces the residency time of urea within the collecting tubules, which in turn reduces the passive reabsorption of urea, and thus compensates for reductions in the efficiency of urea excretion resulting from decreased urea production and reduced urine flow (Bankir et al., 1993; Bankir, 1997). A similar mechanism may exist in fasting elephant seal pups. 
In weanlings, urine flow decreases by $\sim 80 \%$ and urine concentration increases from 1053 to $1585 \mathrm{mOsm} / \mathrm{kg}$ between the first and eighth week of the fast (Adams and Costa, 1993; Ortiz et al., 1996). This is accompanied by a reduction in plasma urea concentration (this study; Adams and Costa, 1993; Houser, 1998). Estimates of the fractional reabsorption of urea (\% reabsorption $=100-[100 \times($ urea excretion $) /($ GFR $\times$ BUN $)])$, using mean GFR from this study and urea excretion rates from Adams and Costa (1993), indicate the fractional reabsorption of urea increased from 80 to $87.3 \%$ between the second and eighth week of the fast. If GFR were depressed upon entrance into the fast, or declined across the fast, residency time of urea within the collecting tubules would increase and result in a greater fractional reabsorption of urea than that observed (i.e. even less efficient urea excretion). GFR in weanlings may thus compensate for reductions in urea excretion efficiency that result from the fasting-related decline in serum urea concentration. If such a renal mechanism exists within elephant seals, then it may be remarkably flexible, as GFR demonstrates considerable variation between individual fasting weanlings and lactating females (Crocker et al., 1998).

Typical correlates of GFR, such as mass and the ratio of BUN to creatinine, were poor predictors of renal filtration in this study. Within fasting weanlings, it is possible that the use of dissociative drugs for immobilization affected renal function. This could obscure relationships with biochemical or morphological predictors and invalidate the measurements of GFR. Dissociatives (e.g. ketamine and tiletamine) are known to increase mean arterial pressure and heart rate in a number of domesticated and exotic species, as well as humans (Domino et al., 1965; Tweed et al., 1972; Kreeger et al., 1990; Wilson et al., 1993; Caulkett and Cattet, 1997). This increase in mean arterial pressure can elevate GFR; however, unless renal arterial pressure exceeds the limits of autoregulation, tubuloglomerular and myogenic mechanisms act to stabilize GFR to normal rates. Values and variability of GFR in this study were similar to those obtained by Pernia et al. (1989) for manually restrained, fasting weanlings. Since GFR was similar between both chemical and manual immobilization, it is presumed that GFR was not affected through the administration of dissociatives and that any effects upon mean arte- rial pressure were accommodated through autoregulatory mechanisms.

During the 4-week suckling period, pups nearly triple their mass and deposit a considerable amount of adipose tissue, increasing adipose composition from $9 \%$ of mass at birth to nearly $50 \%$ of mass at weaning (Ortiz et al., 1978; Rea and Costa, 1992; Kretzmann et al., 1993; Crocker, 1995). This deposition of poorly hydrated and relatively metabolically inert tissue may underlie the lack of a correlation between mass and GFR observed here, and the weak correlation observed by Pernia et al. (1989). The ECV, the actual fluid volume filtered by the kidney, should correlate with renal function (Gunasekera et al., 1996), and Pernia et al. (1989) found this to be the case $\left(R^{2}=0.76\right)$. To calculate ECV via the distribution of an exogenous tracer, the distribution of tracer transit times within the ECV must remain unchanged (Ladegaard-Pedersen, 1972). This assumption is potentially violated to a considerable degree in pinnipeds, which are capable of dramatic redistributions of blood flow via selective ischemia (Bron et al., 1966; Zapol et al., 1979). In this study, occasional rises in $\left[{ }^{3} \mathrm{H}\right]$ inulin clearance curves suggested that the distribution of transit times of the tracer in ECV may have changed and, in several instances, reported values for the ECV exceeded physiological expectation. This discrepancy with previous investigations (Pernia et al., 1989) suggests that interpretations of physiological function based upon values of ECV should be cautiously undertaken, and that alternative methods for evaluating the ECV need to be investigated in order to verify or invalidate the results obtained so far.

An $84 \%$ reduction in urine flow across the fast, and a concomitant increase in urine concentration without a reduction in GFR, indicates that tubular water reabsorption improves with time fasting (Pernia et al., 1989; Adams and Costa, 1993). Vasopressin and aldosterone both affect water reabsorption in the renal tubule, but little is known of their respective water conservation roles in fasting elephant seals. The serum concentration of vasopressin, the primary hormone underlying urine concentration in most mammals, declines as urine osmolarity increases in fasting elephant seal pups (Ortiz et al., 1996). This suggests that vasopressin is not primarily responsible for reducing the water content of urine across the fast. Aldosterone affects water reabsorption via 
sodium transport, but in this study aldosterone concentration also declined between the second and eighth week of the fast. The sampling scheme employed in this study may be misleading, however, since recent data indicate aldosterone concentration increases approximately five-fold during the first 5 weeks of fasting (from $\sim 200$ to $\sim 1100 \mathrm{pg} / \mathrm{ml}$ ) and begins to decrease (down to $\sim 990 \mathrm{pg} / \mathrm{ml}$ ) during the seventh week (Ortiz et al., 2000). This pattern is consistent with the results presented here and mirrors changes in urine osmolarity previously reported; urine osmolarity increases up through the eighth week of the fast and then declines (Ortiz et al., 1996). This correlation with changing urine osmolarity suggests that aldosterone plays a significant role in regulating urine concentration.

Excretion of sodium declines across the fast (Ortiz et al., 1996), but serum sodium remains stable within narrow limits (Costa and Ortiz, 1982). Since reduced urine $\left[\mathrm{Na}^{+}\right]$forms a concentration gradient favorable to sodium excretion, a renal mechanism must exist to transport sodium across the tubular epithelium and back into circulation. Aldosterone accomplishes this task through a concentration-dependent activity in the collecting duct, an action that consequently promotes water reabsorption via solvent drag. Thus, aldosterone likely serves an important role in both urine concentration and electrolyte balance. The response of aldosterone production to salt loading and a more robust determination of how serum aldosterone concentration, serum osmolarity, and urine osmolarity simultaneously change across the fast should be investigated to clarify the manner in which aldosterone functions in the fasting elephant seal.

Elephant seal pups demonstrate a unique and labile system of renal function that deviates from the mammalian norm. Similarity in GFR exists between pups engaged in feeding and fasting. We propose two hypotheses as explanations for this observation. First, a postprandial hyperfiltration may be unnecessary while suckling, due to low protein oxidation and the rapid recruitment of protein for tissue synthesis. Second, maintenance of GFR at rates similar to suckling may benefit fasting animals by compensating for the reduction in the fractional excretion of urea that accompanies a simultaneous reduction in urea production and urine flow. Aldosterone is a likely candidate for the primary control of water reabsorption, but further work needs to be conducted to determine its control over sodium and water reabsorption and its relationship to GFR as part of the urinary concentrating mechanism.

\section{Acknowledgements}

The authors would like to thank D. Waples, S. Hayes, and D. Hyrenbach for assistance in data collection. We would also like to thank the rangers of Año Nuevo State Reserve for their cooperation during the study. Support for this project was obtained from the Friends of Long Marine Laboratory, Scripps Institution of Oceanography, as part of the ATOC project (ARPA MDA 97293-1-003), and the Office of Naval Research (NOOO14-94-1-455). All procedures used in this study were approved by the IUCAC of the University of California, Santa Cruz, and performed under Marine Mammal Protection Act permit no. 836.

\section{References}

Adams, S.H., Costa, D.P., 1993. Water conservation and protein metabolism in northern elephant seal pups during the postweaning fast. J. Comp. Physiol. B 163, 367-373.

Bankir, L., 1997. Vasopressin and water conservation: the good and the evil. Am. J. Kidney Dis. 30, 44-46.

Bankir, L., Ahloulay, M., Bouby, N. et al., 1993. Is the process of urinary urea concentration responsible for a high glomerular filtration rate? J. Am. Soc. Nephrol. 4, 1091-1103.

Blackwell, S.B., Le Boeuf, B.J., 1993. Developmental aspects of sleep apnoea in northern elephant seals, Mirounga angustirostris. J. Zool. Lond. 231, 437-447.

Boim, M.A., Schor, N., 1992. Renal sodium conservation during starvation in rats. Braz. J. Med. Biol. Res. 25, 1209-1213.

Bosch, J.P., 1995. Renal reserve: a functional view of glomerular filtration rate. Semin. Nephrol. 15, 381-385.

Briggs, G.D., Henrickson, R.V., Le Boeuf, B.J., 1975. Ketamine immobilization of northern elephant seals. J. Am. Vet. Med. Assoc. 167, 546-548.

Bron, K.M., Murdaugh, J.H.V., Millen, J.E., Lenthall, R., Raskin, P., Robin, E.D., 1966. Arterial constrictor response in a diving mammal. Science 152, 540-543.

Brown, D.C., Mulhausen, R.O., Andrew, D.J., Seal, U.S., 1971. Renal function in anesthetized dormant and active bears. Am. J. Physiol. 220, 293-298. 
Castellini, M.A., Costa, D.P., Huntley, A.C., 1987. Fatty acid metabolism in fasting elephant seal pups. J. Comp. Physiol. B 157, 445-449.

Caulkett, N.A., Cattet, M.R.L., 1997. Physiological effects of medetomidine-zolazepam-tiletamine immobilization in black bears. J. Wildl. Dis. 33, 618-622.

Condit, R.S., Ortiz, C.L., 1987. The physiological transition from fasting to feeding in weaned elephant seal pups. Mar. Mammal Sci. 3 (3), 207-219.

Costa, D.P., Ortiz, C.L., 1982. Blood chemistry homeostasis during prolonged fasting in the northern elephant seal. Am. J. Physiol. 242, R591-R595.

Costa, D.P., Le Boeuf, B.J., Huntley, A.C., Ortiz, C.L., 1986. The energetics of lactation in the northern elephant seal, Mirounga angustirostris. J. Zool. Lond. 209, 21-33.

Crocker, D.E., 1995. Reproductive Effort and Fasting Physiology of Female Northern Elephant Seals, Mirounga angustirostris. Department of Biology, University of California Santa Cruz, Santa Cruz (Ph.D. thesis, $118 \mathrm{pp}$ ).

Crocker, D.E., Webb, P.M., Costa, D.P., Le Boeuf, B.J., 1998. Protein catabolism and renal function in lactating northern elephant seals. Phys. Zool. 71 (5), 485-491.

Domino, E.F., Chodoff, P., Corssen, G., 1965. Pharmacologic effects of CI-581, a new dissociative anesthetic in man. Clin. Pharmacol. Ther. 6, 279-291.

Finko, D.R., Brown, S.A., Vaden, S.L., Ferguson, D.C., 1995. Relationship between plasma creatinine concentration and glomerular filtration rate in dogs. J. Vet. Pharmacol. Therap. 18, 418-421.

Gunasekera, R.D., Allison, D.J., Peters, A.M., 1996. Glomerular filtration rate in relation to extracellular fluid volume: similarity between ${ }^{99 \mathrm{~m}}$ Tc-DTPA and inulin. Eur. J. Nucl. Med. 23, 49-54.

Hall, J.E., Guyton, A.C., Farr, B.M., 1977. A single-injection method for measuring glomerular filtration rate. Am. J. Physiol. 232, F72-F76.

Hiatt, E.P., Hiatt, R.B., 1942. The effect of food on the glomerular filtration rate and renal blood flow in the harbor seal (Phoca vitulina L.). J. Cell Comp. Physiol. 19, 221-227.

Hladky, S.B., Rink, T.J., 1986. Body fluid and kidney physiology. In: Hobsley, M., Saunders, K.B., Fitzsimmons, J.T. (Eds.), Physiological Principles in Medicine. Edward Arnold Ltd, London (239 pp).

Houser, D.S., 1998. The Limitations and Characterization of Protein and Water Conservation in Pups of a Fasting Adapted Species, Mirounga angustirostris. University of California, Santa Cruz (Ph.D. thesis, $127 \mathrm{pp})$.

Huntley, A.C., Costa, D.P., Rubin, R.D., 1984. The contribution of nasal countercurrent heat exchange to water balance in the northern elephant seal, Mirounga angustirostris. J. Exp. Biol. 113, 447-454.

Kreeger, T.J., Seal, U.S., Callahan, M., Beckel, M., 1990. Physiological and behavioral responses of gray wolves (Canis lupus) to immobilization with tiletamine and zolazepam. J. Wildl. Dis. 26, 90-94.

Kretzmann, M.B., Costa, D.P., Le Boeuf, B.J., 1993. Maternal energy investment in elephant seal pups: evidence for sexual equality? Am. Nat. 141, 466-480.

Ladegaard-Pedersen, H.J., 1972. Measurement of extracellular volume and renal clearance by a single injection of inulin. Scand. J. Clin. Lab. Invest. 29, 145-153.

Le Boeuf, B.J., 1974. Male-male competition and reproductive success in elephant seals. Am. Zool. 14, 163-176.

Le Boeuf, B.J., Peterson, R.S., 1969. Social status and mating activity in elephant seals. Science 163, 91-93.

Le Boeuf, B.J., Whiting, R.J., Gantt, R.F., 1972. Perinatal behavior of northern elephant seal females and their young. Behavior 43, 121-156.

Nelson, R.A., Wahner, H.W., Jones, J.D., Ellefson, R.D., Zollman, P.E., 1973. Metabolism of bears before, during, and after winter sleep. Am. J. Physiol. 224, 491-496.

Ortiz, C.L., Costa, D.P., Le Boeuf, B.J., 1978. Water and energy flux in elephant seal pups fasting under natural conditions. Physiol. Zool. 51, 166-178.

Ortiz, C.L., Le Boeuf, B.J., Costa, D.P., 1984. Milk intake of elephant seal pups: an index of parental investment. Am. Nat. 124, 416-422.

Ortiz, R.M., Adams, S.H., Costa, D.P., Ortiz, C.L., 1996. Plasma vasopressin levels and water conservation in fasting postweaned northern elephant seal pups (Mirounga angustirostris). Mar. Mammal Sci. 12, 99-106.

Ortiz, R.M., Wade, C.E., Ortiz, C.L., 2000. Prolonged fasting increases the response of the renin-angiotensin-aldosterone system, but not vasopressin levels, in postweaned northern elephant seal pups. Gen. Comp. Endocrinol. 119, 217-223.

Pernia, S.D., Costa, D.P., Ortiz, C.L., 1989. Glomerular filtration rate in weaned elephant seal pups during natural, long-term fasts. Can. J. Zool. 67, 1752-1756.

Pullman, T.N., Alving, A.S., Dern, R.J., Landowne, M., 1954. The influence of dietary protein intake on specific renal functions in normal man. J. Lab. Clin. Med. 44, 320.

Rea, L.D., Costa, D.P., 1992. Changes in standard metabolism during long-term fasting in northern elephant seal pups (Mirounga angustirostris). Physiol. Zool. 65, 97-111.

Reiter, J., Panken, K.J., Le Boeuf, B.J., 1981. Female competition and reproductive success in northern elephant seals. Anim. Behav. 29, 670-687. 
Reiter, J., Stinson, N.L., Le Boeuf, B.J., 1978. Northern elephant seal development: the transition from weaning to nutritional independence. Behav. Ecol. Sociobiol. 3, 337-367.

Thorson, P.H., Le Boeuf, B.J., 1994. Developmental aspects of diving in northern elephant seal pups. In: Le Boeuf, B.J., Laws, R.M. (Eds.), Elephant Seals: Population Ecology, Behavior, and Physiology. University of California Press, Berkeley, pp. 271-289.

Tweed, W.A., Minuck, M.S., Mymin, D., 1972. Circula- tory response to ketamine anesthesia. Anesthesiology 37, 613-619.

Wilson, R.P., Zagon, I.S., Larach, D.R., Lang, C.M., 1993. Cardiovascular and respiratory effects of tiletamine-zolazepam. Pharmacol. Biochem. Behav. 44, $1-8$.

Zapol, W.M., Liggins, G.C., Schneider, R.C. et al., 1979. Regional blood flow during simulated diving in the conscious Weddell seal. J. Appl. Phys. 47, 968-973. 